\title{
Effect of Urbanization on Land use Land Cover in Gombe Metropolis
}

\author{
L.A. Mbaya ${ }^{1}$, G. O. Abu ${ }^{1}$, Yila Caiaphas Makadi ${ }^{1}$, D.M. Umar ${ }^{2}$ \\ ${ }^{1}$ Department of Geography, Gombe State University, Gombe, Nigeria \\ ${ }^{2}$ Department of Biological sciences, Gombe State University, Gombe, Nigeria \\ E-mail: cial0522@yahoo.com
}

\begin{abstract}
This study examined the integration of Remote Sensing and Geographic Information System (RS/GIS) for analyzing land use and land cover dynamics in Gombe Metropolitan, the Gombe State capital for the period 1976 to 2016. Land sat (TM) images of 1976, 1996and 2016 were used. The study employed supervised digital image classification method using Erdas Imagine 9.2 and Arc GIS 10.5 software and classified the land use into undisturbed vegetation, sparse vegetation, Settlements, Farmlands, Rock outcrops, Bare surfaces. The images were analyzed via georeferencing, image enhancement, image resampling and classification. The results obtained show an increasing settlements (from 0.36\% - 4.01\%) and farmlands (from $24.8 \%$ - 51.2\%), over a decreasing of other LULC classes (bare surfaces, undisturbed and sparse vegetation, and rocky outcrops) for the time period of 1976 to 2016. These results could help city planners and policy makers to attain and sustain future urban development. It is therefore recommended that encouragement should be given to people to build towards the outskirts, like New mile 3 and Tumfure, etc through the provision of incentives and forces of attraction that is available at the city center in these areas to avoid the problem of overcrowdings.
\end{abstract}

Keywords: Urbanization, Land Use/Cover, Change Detection, Gombe, Remote Sensing, GIS.

\section{INTRODUCTION}

Land is the most important natural resources on which all activities are based. Land use unlike geology, is seasonally dynamic and indeed is more changing. The increase in population and human activities are increasing the demand on the limited land and soil resources for agriculture, forest, pasture, urban and industrial land uses. Information on the rate and kind of changes in the use of land resources is essential for proper planning, management and to regularise the use of such resources.

Land use / land cover are very dynamic in nature and have to be monitored at regular intervals for sustainable environmental development (Zubair, 2006). Population is a very important factor or agent of change in land-use in an area. For instance, as population increases, construction of dwellings increases, thus engendering conversion of cropland and forest land to settlements. These urban land-uses are of various types which could be for industrial, commercial, government, as well as transportation purposes.

The most obvious effect of urbanization - an effect which is implicit in its definition is an intensification, as well as diversification, of environmental resource exploitation. There are usually changes in the land cover and landscape pattern brought about by the shift from less intensive to more intensive uses of land. Such diversification of environmental resources exploitation is accompanied by increases in environmental degradation. By environmental degradation, it is meant the long-term loss in ecosystem function and productivity. Its symptoms include soil erosion, nutrient depletion, salinity, water scarcity, pollution, disruption of biological cycles, and loss of biodiversity (UNCED, 1992).

Urbanization is the driving force for modernization, economic growth and development, there is yet an increasing concern about the effects of expanding cities, principally on human health, livelihoods and the environment (UN-Habitat, 2003). Rapid urbanization, particularly the growth of large cities 
especially in Nigeria, is often associated with problems such as unemployment, poverty, inadequate health facilities, poor sanitation, urban slums and general environmental degradation (UNDP, 2008). All these pose a formidable challenge in many developing countries. The question that arises is whether the current trend in urban growth is sustainable, considering the accompanying urban challenges, especially in the developing countries (UNDP, 2008).

Studies have shown that there remains only few landscapes on the earth that still exist in their natural state. Due to anthropogenic activities, the earth's surface is being significantly altered and man's presence on the earth and his use of land has had a profound effect upon the natural environment, thus resulting into an observable pattern in the land use/land cover over time (Lambin, Geist and Lepers, 2003; Zubair, 2006; Long, et. al.,2008).

Ademiluyi, et al., (2008) said rapid urbanization/industrialization and large scale agriculture and major changes in human activities have been identified as the major causes of the dramatic changes in land cover and land use patterns globally. Urban centers in Nigeria are facing the problems of over-stretched infrastructures, environmental degradation, seasonal flooding, destruction of natural vegetation, all resulting from increase in population (Joel, 2006).

The movement of people from rural to urban cities in search of better livelihood lead to an expansion of urban areas and increase in social and economic activities along flood plains thus increasing the risk of urban dwellers and infrastructures to natural disasters such as floods (Akinbami, Akinwumi and Salami, 1996; Ishaya, Ifetimehin and Okafor, 2008). The need for quantitative information on the environmental consequences of expansion of cities in Nigeria provided the basis for this study.

The aim of this study is to corroborate the increasing problem of urbanization on other land uses. The study explored the implications of the increasing urban expansion, spurred up by population growth, for environmental sustainability especially in Nigeria. Needless to state that the attainment of sustainable development will remain a mirage in Gombe in particular and Nigeria in general, if the current rate of urban population growth (such as natural increase and migration) and increasing environmental decay are not matched with proportionate economic growth and environmentally friendly development practices.

\section{METHODS}

The study area is Gombe town and, it is located on latitude $10^{\circ} 13^{\prime}$ and $10^{\circ} 20^{\prime} \mathrm{N}$ and longitude $11^{0} 02^{\prime}$ and $11^{0} 16^{\prime} \mathrm{E}$. The study area is limited to the urban area and environs. Some $9 \mathrm{~km}$ radius around the town has been arbitrarily demarcated for the study with Union Bank round about, along Biu Road being the centre point (Fig.1).Gombe is located within the sub-Sahara climatic zone. It is characterized by two distinctive seasons, that is, dry season (November-April) and wet season (May-October). The dry season comes with the north-east trade winds over the region originating from Sahara belt. The wind is dry and dust laden accompanied by low pressure system. The wet season comes with the south-Westerly wind which is moisture laden, and originates from high pressure zone over the Atlantic Ocean to the low pressure zone over the Sahara. The rainfall here averages $907 \mathrm{~mm}$. The vegetation of Gombe is within Sudan/Guinea savannah. This is characterized by shrubs and scattered trees with a different species of grasses. The soils are highly ferruginous, formed as a result of intensive weathering of the basement rocks.

The datasets used in this study were mainly derived from Landsat imageriesacquired in 1976, 1996 and 2016Theses imageries were sourced fromone of the USGS websites; (https://glovis.usgs.gov/). The characteristics of theimages are shown in Table 1. The Geo-information software used includes;IDRISI version 18 and ArcGIS, 10.0. The IDRISI Terrset was used in the image processing and analysis, while the 
ArcGIS was used for visualization of the processedimages.Area of Interest (AOI) was extracted from the four (4) Landsat scenes usingthe "Window" tool in IDRISI. False Colour Composite (RGB) of the three bandsfor each of the selected dates was made in order to increase the pictorial qualityfor easy visual interpretation and identification of features on the images. Theimages were further subjected to geometric correction using the "Resampling"technique. This is carried out in order to co-register the images as suggested. The images were classified using the Maximum Likelihood algorithm intosix classes (settlements, bare surfaces, undisturbed and sparse vegetation, rocky outcrops and farmlands).

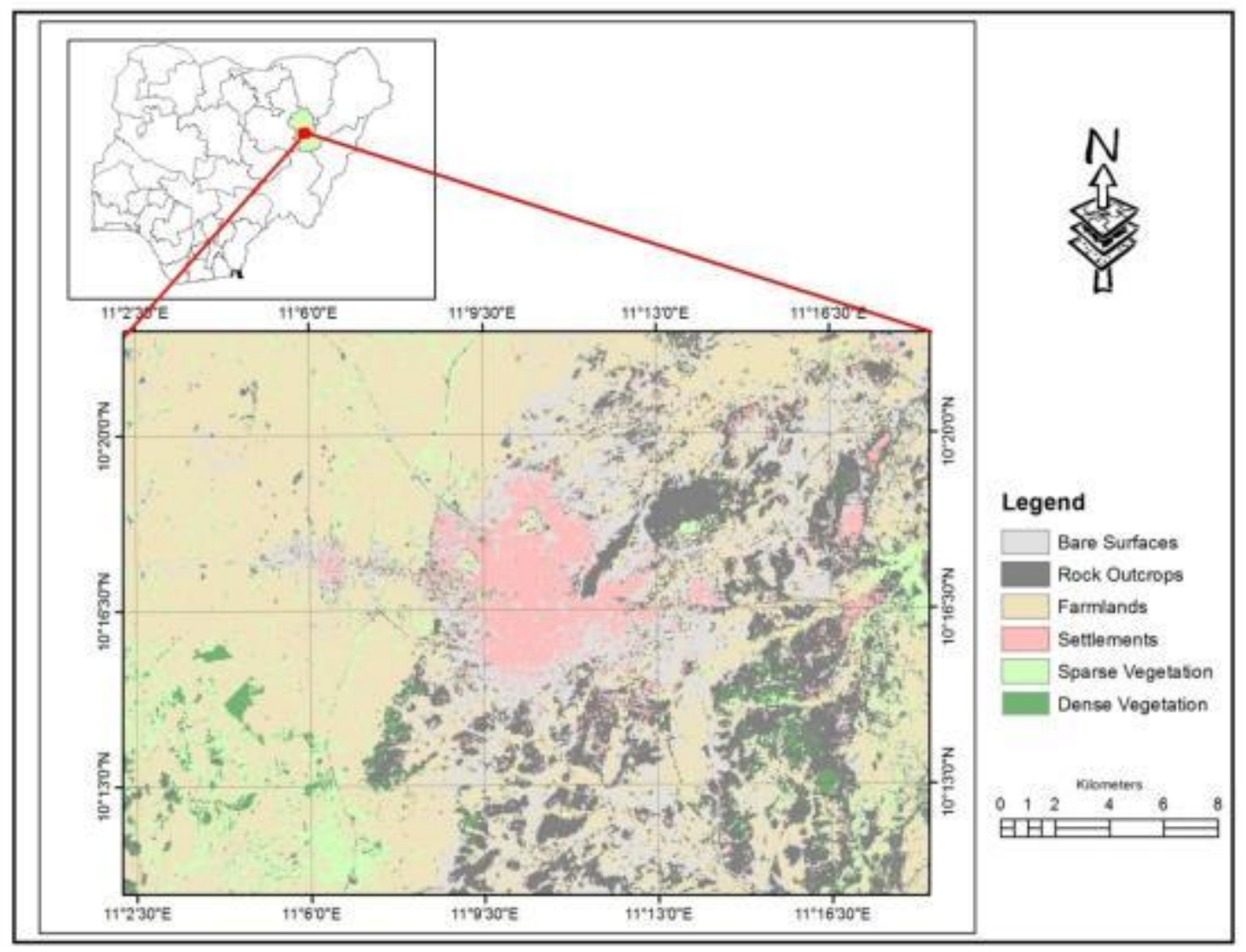

Figure 1: The Study Area

\section{Procedure for Data Collection}


The characteristics of the satellite images used in this study are contained in Table 1.

Table 1: Characteristics of Satellite Imageries

\begin{tabular}{llll}
\hline Date of acquisition & Type of satellite image & $\begin{array}{l}\text { Spatial } \\
\text { (m) }\end{array}$ & resolution \\
1976 & Landsat Multi Spectral Scanner (MSS) & 30 \\
1996 & Landsat Thematic mapper (TM) & 30 \\
2016 & Landsat Thematic mapper (TM) & 30 \\
\hline
\end{tabular}

The remote sensing and the geographic information system (GIS) technology and applications were applied in the determination of the land cover changes.The interpretation and classification of satellite images involved subsetting and other pre-processing steps including georeferencing,colour composite and unsupervised classification; ground truthing, screen digitization of some features, supervised classification and change detection. Subsetting consisted mainly in selecting and extracting the study area from the full scene images. Colour composite and unsupervised classification enabled us to establish major land cover classes before ground truthing to match the reality in the field with the classified image. After ground truthing, the supervised classification enabled to proceed on land cover map composition for each image.

\section{Data Analysis}

The obtainedresult was analyzed using tables and maps. The size and area of the land cover changes were calculated and represented in hectares. The rationale for these was based on the total size of the study area.

\section{RESULTS AND DISCUSSION}

Sequel to the general objective of this study, it was observed that there was an exponential growth in the city which have led to the quest for land, housing and other facilities/infrastructures that have given rise to changes in land cover, thus, reduction and loss of other land uses.

Figures 1, 2 and 3 present the LULC of the study area during the study period. The statistics of the land use/land cover distribution for each study year as derived from the imageries is presented in Table 2.

The supervised classification system using the maximum likelihood classifier as explained in the methodology was used for the analyses of the imageries. Figures 1, 2 and 3 shows the classified maps adopted in this study.

\section{Table 2: Land-use/Land Cover Distribution}




\begin{tabular}{lrrrrrr}
\hline Land use classes & $\begin{array}{c}\mathbf{1 9 7 6} \\
\text { (hectares) }\end{array}$ & \multicolumn{1}{c}{ \% } & \multicolumn{1}{c}{$\begin{array}{c}\mathbf{1 9 9 6} \text { (hectares) } \\
\text { \%o }\end{array}$} & \multicolumn{1}{c}{$\begin{array}{c}\text { 2016 } \\
\text { (hectares) }\end{array}$} & \multicolumn{1}{c}{ \% } \\
\hline Undisturbed vegetation & 21374.37 & 23.75 & 6052.50 & 6.70 & 1235.52 & 1.37 \\
\hline Sparse vegetation & 33986.25 & 37.76 & 18373.77 & 20.42 & 8721.90 & 9.69 \\
\hline Settlements & 324.45 & 0.36 & 978.84 & 1.09 & 3615.03 & 4.01 \\
\hline Farmlands & 22327.56 & 24.81 & 38697.12 & 43.00 & 46112.94 & 51.24 \\
\hline Rock outcrops & 1962.45 & 2.18 & 13916.34 & 15.46 & 15286.95 & 16.99 \\
\hline Bare surfaces & 10024.92 & 11.14 & 11981.43 & 13.31 & 15027.66 & 16.70 \\
\hline Total & $\mathbf{9 0 , 0 0 0}$ & $\mathbf{1 0 0}$ & $\mathbf{9 0 , 0 0 0}$ & $\mathbf{1 0 0}$ & $\mathbf{9 0 , 0 0 0}$ & $\mathbf{1 0 0}$ \\
\hline
\end{tabular}

The supervised classification system using the maximum likelihood classifier as explained in the methodology was used for the analyses of the imageries. Figures 1, 2 and 3 shows the classified maps adopted in this study.

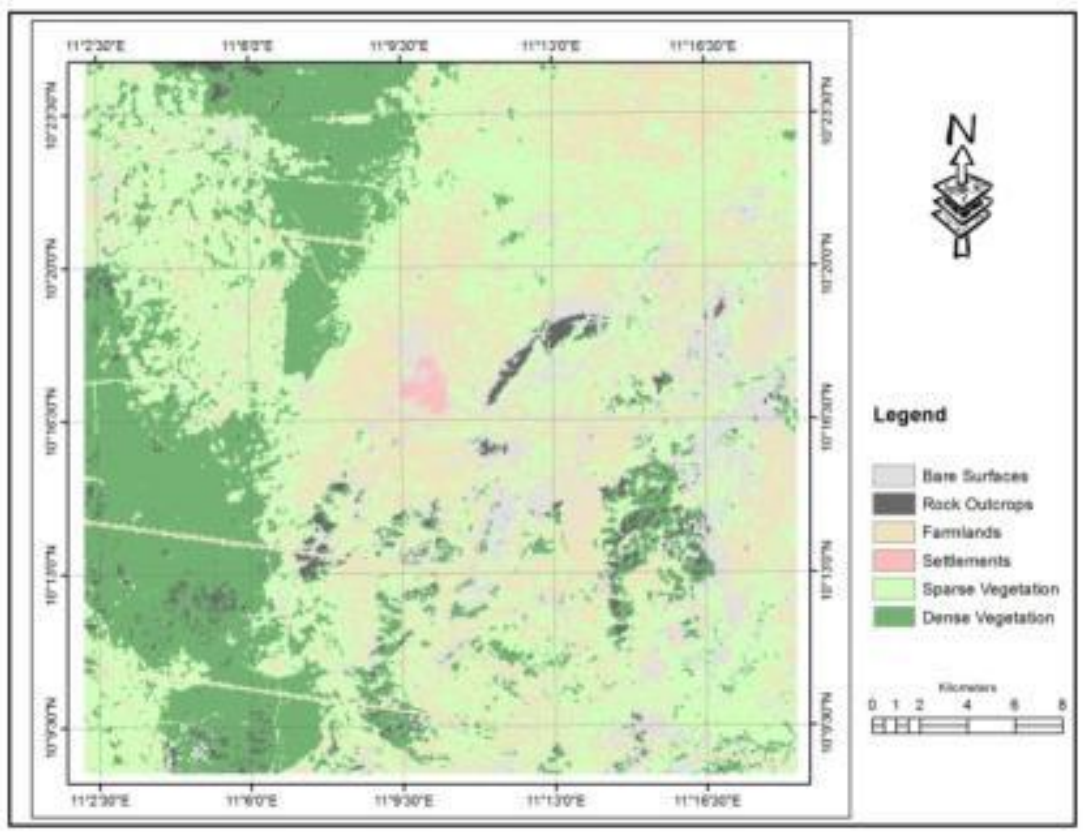

Figure 1: Classified Land Use Land Cover of 1976 


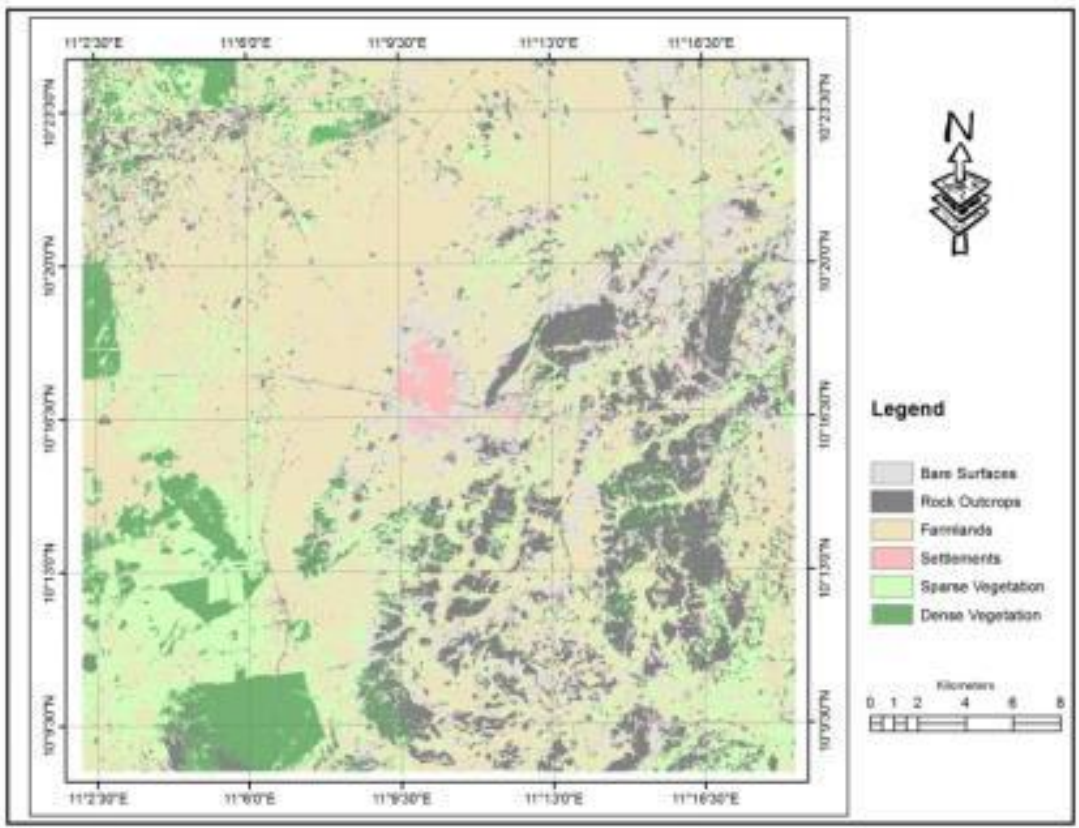

Figure 2: Classified Land Use Land Cover of 1996

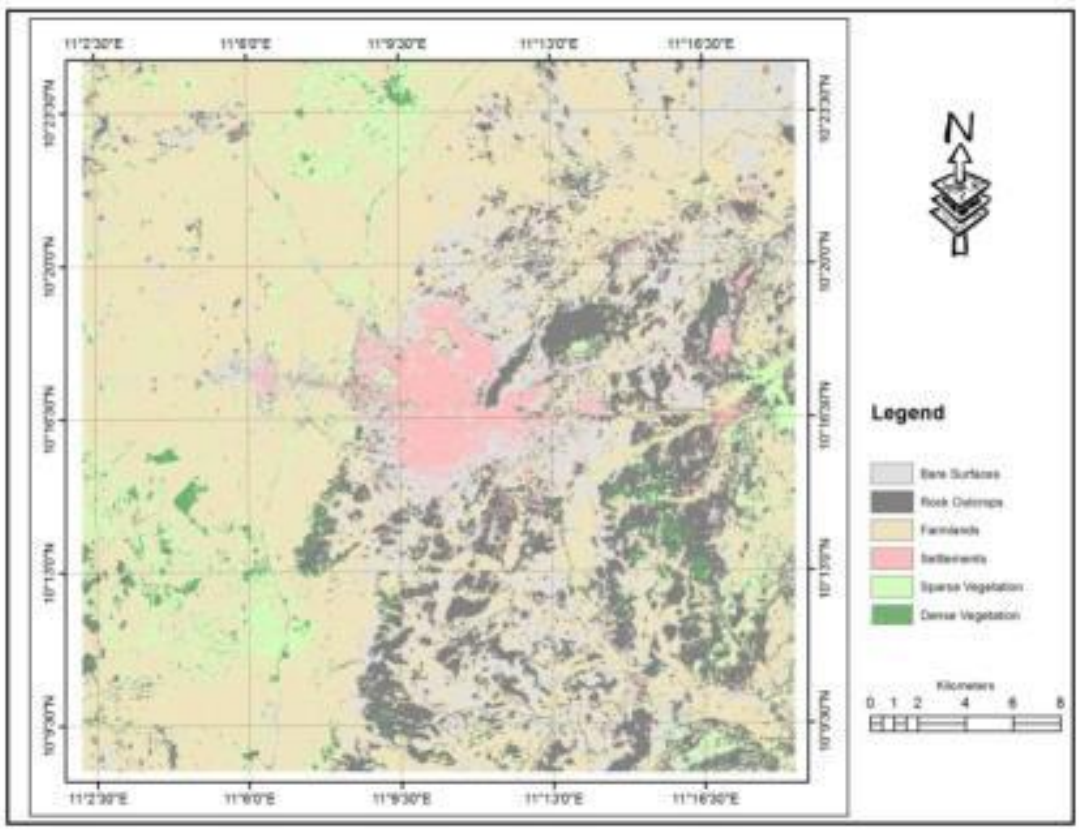

Figure 3: Classified Land Use Land Cover of 2016

As shown in Figure 4.4, the land-use/ land-cover distribution pattern in the year 1976 shows that sparse vegetation occupies 38\% of the land-use category in the study area, followed by farmlands and undisturbed vegetation with a percentage of $25 \%$ and $24 \%$ respectively. This means that the vegetation as at then was readily abundant and there was available farmland with less competition on landuses. The bare surfaces had about $11 \%$ while rock outcrops had only $2 \%$. The least of the landuse was settlement which occupies about $0.4 \%$. 
The land-use/land-cover distribution for 1996 also shows that farmland occupies over half of the land-use distribution (43\%) with almost two times increase from the 1976. This isfollowed by sparse vegetation $20 \%$ a decrease from 1976 land-usedistribution, others on the increase are also rock outcrops, bare surfaces and settlements having $15 \%, 13 \%$ and $1 \%$ respectively. However, the undisturbed vegetation reduced to about $7 \%$ due to increase in settlements and farmlands.

In 2016, the land-use distribution shows increased in settlement which occupies $4 \%$, while the farmlands occupied $51 \%$ of the land-use distribution making it the highest land-use/ land-cover category in the study area. Undisturbed vegetation showed a decrease occupying only $1 \%$ of the total area. The remaining land-cover categories of rock outcrop (17\%) and bare surfaces (17\%) showed an increase in these areas compared to the previous years except sparse vegetation that also showed a rapid decrease to $10 \%$ from $38 \%$ of 1976 and this is attributed to land-use conversion for other urban activities and increased population pressure.This conforms to the studies of Chigbu, et al.,(2011) who noted a significant disparity and trend in vegetation landcover due to rapid urbanization and socio economic activities. As well as Oluseyi, (2006) that discovered that the land use types that are subject to major changes are vegetal covers and sprawl development.

\section{CONCLUSION}

Urbanization and ineffective legal frameworks had been discovered to be the major impediments to the ever growing land use changes in Nigeria. This has however contributed immensely to the poor economic structures and environmental degradation. The creation of Gombe State and Gombe as a state capital has attracted a lot of people to the area thus contributing to the physical expansion of the city.

Results of this study indicate that, supervised classification provided satisfactory results in terms of distinguishing settlements, bare surfaces, undisturbed and sparse vegetation, rock outcrops and farmlands. The main change observed for the time period of 1976 to 2016 was the decrease of undisturbed and sparse vegetation areas due to urbanization. Settlements are increasing in the study area as well as farmlands. Land use/land cover mapping and detection of changes shown here may not provide the ultimate explanation for all problems related to land use/land cover changes but it serves as a base to understand the patterns and possible causes and consequences of land use/land cover changes in the area.

\section{REFERENCES}

Ademiluyi. A.I., Okude, A.S., and Akanni, C.O. (2008) "An Appraisal of Land Use and Landcover Mapping in Nigeria," African Journal of Agricultural Research, Vol. 3, No. 9, pp. 581-586.

Akinbami, J. F. K, Akinwumi, I. O. and Salami A. T (1996), Implications of environmental degradation in Nigeria, Natural Resources Forum, 20 (4), 319 - 332.

Chigbu,N.Igbokwe,J.I and Orisakwe,K.U (2011).Analysis of Land use Land cover changes of $\quad$ Aba Urban Using medium Resolution Satellite imageries:Bridging the gap between cultures Marrakech, Morocco.

Ishaya S., Ifatimehin, 0.0. and Okafor, C. (2008). Remote Sensing and GIS Applications in Urban Expansionand Loss of Vegetation Cover in Kaduna Town, Northern Nigeria, Am.-Eurasian Journal of Sustainable Agriculture,2(2): 117-124.

Joel,I.I.(2006).Mapping and Spatial Characterization of major urban centers in part of south eastern Nigeria:Promoting Land Administration and Good Governance FIG Regional Conference Ghana. 
Lambin, E. F., Geist, H. J., and Lepers, E. (2003). Dynamics of land-use and land-cover change in tropical regions. Annual Review of Environment and Resources, 28, 205-241.

Long, H., Wu, X., Wang, W. and Dong, G. (2008) "Analysis of Urban-Rural Land-Use Change During 19952006 and Its Policy Dimensional Driving Forces in Chongqing, China".Sensors, 8, 681-699.

Oluseyi, F (2006) Urban Land Use Change Analysis of a Traditional City from Remote Sensing Data:The Case of Ibadan Metropolitan Area, Nigeria Humanity \& Social Sciences Journal 1 (1): 42-64.

UNCED (United Nations Conference on Environment and Development (1992).Agenda 21, Rio de Janeiro.

UN-Habitat, (2003).The Challenge of Slums.Global Report on Human Settlements 2000. Earthscan, London.

UNDP (2008). Human Development Report 2007/2008: Country fact sheets: Nigeria. United Nations, New York.

Zubair, A. O. (2006): Change detection in land use and land cover using Remote Sensing data and GIS (A case study of Ilorin and its environs in Kwara State). M.Sc Project Submitted to theUniversity of Ibadan 